\title{
On-demand electrochemical synthesis of copper(I) triflate and its application in the aerobic oxidation of alcohols
}

Thomas P. Nicholls, ${ }^{a}$ Richard A. Bourne, ${ }^{a}$ Bao N. Nguyen, ${ }^{a}$ Nikil Kapur, ${ }^{b}$ Charlotte. E. Willans*a

\begin{abstract}
An on-demand electrochemical synthesis of copper(I) triflate under both batch and continuous flow conditions has been developed. A major benefit of the electrochemical methodology is that the only by-product of the reaction is hydrogen gas which obviates the need for work-up and purification, and water is not incorporated into the product. Upon completion of the electrochemical synthesis, solutions are directly transferred or dispensed into reaction mixtures for the catalytic oxidation of alcohols with no requirement for work-up or purification.
\end{abstract}

\section{Introduction}

Metal triflates display a wide variety of applications in inorganic chemistry and catalysis in particular. ${ }^{1-4}$ Recent examples show that $\mathrm{Ni}(\mathrm{OTf})_{2}$ displays superior catalytic activity compared to other $\mathrm{Ni}$ salts in $\mathrm{C}-\mathrm{H}$ arylation and $\mathrm{C}-\mathrm{C}$ coupling reactions. ${ }^{5,6} \mathrm{Fe}^{\text {II }}$ or Fe $\mathrm{Fe}^{\text {III }}$ triflate salts have performed better than other Fe salts in oxidation, radical addition, and $\mathrm{C}-\mathrm{O}$ bond silylation. ${ }^{7-9}$ Despite these representative examples and their widespread use in catalysis, there remain challenges associated with the synthesis of metal triflates, which often involves reacting a metal halide with AgOTf. This can result in water being present in the product, halide impurities and difficult removal of silver salts. An electrochemical synthesis of metal triflates, in which hydrogen gas is the only by-product, negates these challenges.

An excellent example of a metal triflate outperforming related metal salts in catalysis is the copper-catalysed aerobic oxidation of alcohols. ${ }^{10-18}$ This transformation is gaining widespread traction throughout academia and industry as a reliable and convenient method to convert alcohols to aldehydes without overoxidation. This reaction utilises an earth-abundant first row transition metal catalyst and molecular oxygen under mild conditions, which provides an environmentally benign methodology that can allow late-stage modification of alcohols. In this instance, $\mathrm{Cu}^{\prime}$ triflate has been found to dramatically increase catalytic activity when compared to either $\mathrm{Cu}^{\prime}$ halides or $\mathrm{Cu}^{\prime \prime}$ triflate. ${ }^{19}$

The use of $\mathrm{Cu}^{\prime}$ triflate presents a specific problem as it is highly sensitive to the presence of oxygen and moisture and will readily oxidise to its $\mathrm{Cu}$ " congener if not stored under inert conditions. Additionally, the weakly coordinating nature of the triflate anion results in a ligand 
or counter anion which is loosely bound to the metal. This provides stability to the metal complex while retaining a high degree of reactivity as it is not encumbered by a more closely bound ligand or counter anion. This allows reactions at the metal centre to proceed in a more facile manner. Owing to the sensitive nature of $\mathrm{Cu}^{\prime}$ triflate an on-demand synthesis is desirable so it can be produced and used immediately before it can degrade.

Current methodologies for the synthesis of $\mathrm{Cu}^{\prime}$ triflate can provide high yields but suffer from several drawbacks including relatively sensitive and expensive reagents, harsh reaction conditions, and complicated purification. There are two commonly used routes to produce $\mathrm{Cu}^{\prime}$ triflate, both of which were developed in the 1970s (Scheme 1). ${ }^{20-23}$ The first involves synproportionation of Cu"(OTf) $)_{2}$ and copper metal in the presence of triflic acid (HOTf). While this method is high yielding, an excess of copper metal is required and vacuum distillation to remove triflic acid and $\mathrm{MeCN}$ is necessary, or the product must be stored as a dilute $\mathrm{MeCN}$ solution with copper metal still present to avoid oxidation (Scheme 1A). The second method involves refluxing $\mathrm{Cu}^{\prime}$ oxide with triflic anhydride in benzene to provide a $\mathrm{Cu}^{\prime}$ triflate $\bullet$ benzene complex (Scheme 1B). ${ }^{24-27}$ This method typically does not deliver full conversion which can complicate purification, and triflic anhydride is expensive and very sensitive to oxygen and moisture. Finally, while $\mathrm{Cu}^{\prime}$ triflate is commercially available, it is often only available in $90 \%$ purity and it must be stored under inert conditions which highlights the desire for an ondemand and scalable synthesis.

A Synproportionation Ogura, 1978

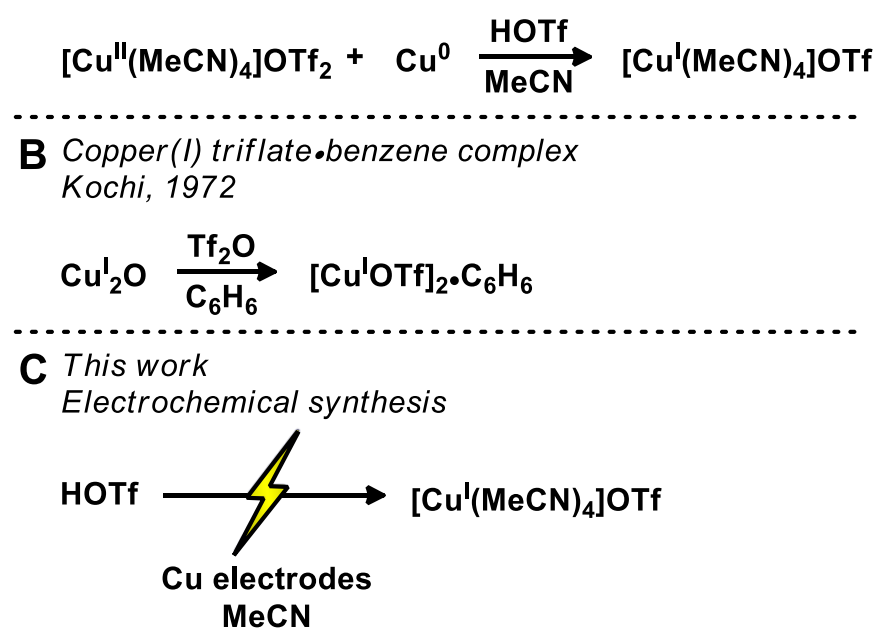

Scheme 1: Established protocols for the synthesis of copper $(\mathbf{I})$ triflate $(\mathbf{A}$ and $\mathbf{B})$ and the protocol developed in this work (C). 
The recent resurgence of electrochemistry provides an opportunity to dramatically improve the synthesis of $\mathrm{Cu}^{\prime}$ triflate and to develop on-demand and clean access (Scheme 1C). ${ }^{28-31} \mathrm{It}$ was envisioned that this route would allow a reaction solution to be used directly in a subsequent catalytic step without any purification or removal of solvent. This is particularly attractive for the aerobic oxidation of alcohols developed by Stahl and co-workers. This copper-catalysed protocol provides facile access to aldehydes without overoxidation to carboxylic acids. ${ }^{32-35} \mathrm{Cu}^{\prime}$ triflate is an excellent catalyst for this transformation as significant rate enhancements are observed when compared to $\mathrm{Cu}^{\prime}$ halides or $\mathrm{Cu}^{\prime \prime}$ triflate. The mechanism of this reaction has been studied extensively, ${ }^{36-39}$ it can be conducted in both batch and continuous flow, ${ }^{40,41}$ and a process development approach has been used for scale-up. ${ }^{42}$ While many aspects of this process have been optimised, the use of sensitive $\mathrm{Cu}$ ' triflate remains the catalyst of choice.

\section{Results and discussion}

Our investigations began by examining the electrochemical synthesis of $\left[\mathrm{Cu}(\mathrm{MeCN})_{4}\right] \mathrm{OTf}$ using only triflic acid, copper electrodes and acetonitrile as starting materials. It was expected that protons from triflic acid would be reduced to hydrogen gas leaving a triflate anion which could unite with $\mathrm{Cu}^{\prime}$ ions released from the sacrificial anode. ${ }^{43,44}$ The galvanostatic mode of operation was chosen as selectivity was not anticipated to be a problem given the low reduction potential of protons $\left(2 \mathrm{H}^{+}+2 \mathrm{e}^{-} \rightarrow \mathrm{H}_{2}, \mathrm{E}^{0}=0 \mathrm{~V}\right.$ vs SHE). ${ }^{45,46}$ Likewise, the oxidation of the sacrificial copper anode only requires $0.52 \mathrm{~V}$ vs SHE. ${ }^{46}$ Acetonitrile was chosen as the solvent due to its good stability under electrolysis and its coordinating ability and affinity for $\mathrm{Cu}^{\prime}$. Stabilisation of the $\mathrm{Cu}^{\prime}$ ion occurs through coordination of four acetonitrile molecules. ${ }^{47}$ As such, the initial reaction conditions chosen for batch electrolysis were triflic acid $(2.0 \mathrm{mmol}), 0.1 \mathrm{M}$ in $\mathrm{MeCN}$, galvanostatic mode ( $\left.50 \mathrm{~mA}, 2.2 \mathrm{~F} \mathrm{~mol}^{-1}\right)$, Cu electrodes, under an inert atmosphere of argon to avoid oxidation to $\mathrm{Cu}^{\prime \prime}$ species (Scheme 2A). Under these conditions, an isolated yield of $96 \%$ $\left[\mathrm{Cu}(\mathrm{MeCN})_{4}\right]$ OTf was obtained after recrystallisation from $\mathrm{MeCN} / \mathrm{Et}_{2} \mathrm{O}$.

The isolated $\left[\mathrm{Cu}(\mathrm{MeCN})_{4}\right]$ OTf was then utilised in an aerobic oxidation of benzyl alcohol following a procedure reported by Stahl and co-workers which resulted in $98 \%$ conversion to benzaldehyde (Scheme 2B). ${ }^{19}$ These encouraging results prompted us to explore the potential of the electrochemical synthesis of $\left[\mathrm{Cu}(\mathrm{MeCN})_{4}\right] \mathrm{OTf}$ in an 'on-demand' fashion in which the complex is synthesised as it is needed and is transferred to a subsequent reaction without purification or removal of solvent. 


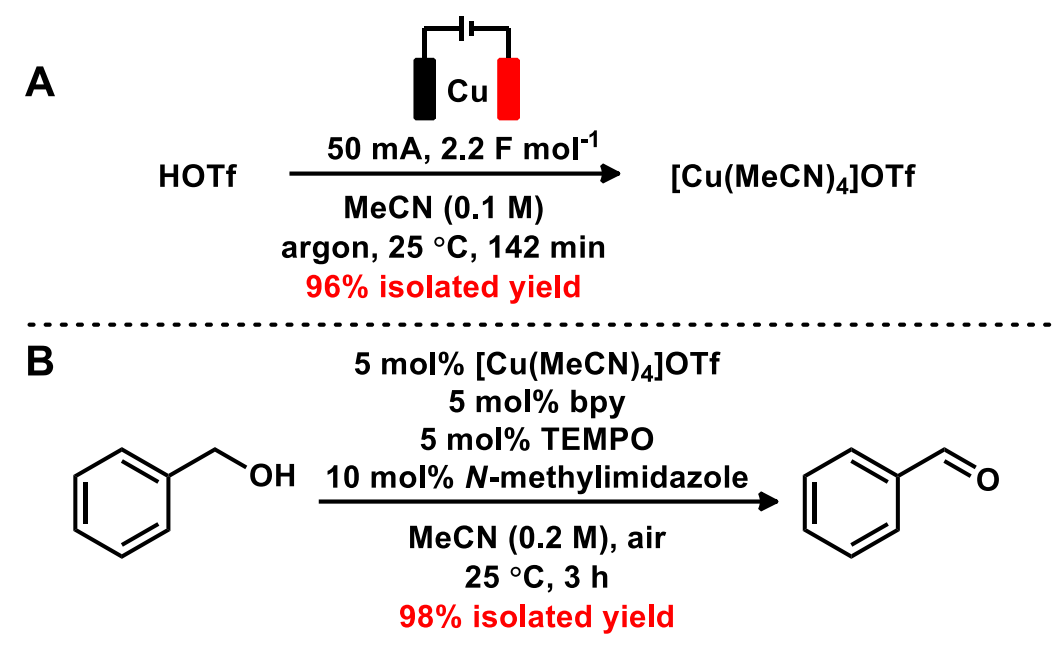

Scheme 2: Step-by-step synthesis of $\left[\mathrm{Cu}\left(\mathrm{MeCN}_{4}\right)\right] \mathrm{OTf}(\mathbf{A})$ and its subsequent use in a Stahl oxidation (B).

As such, $\left[\mathrm{Cu}(\mathrm{MeCN})_{4}\right]$ OTf was synthesised as above and an aliquot containing 5 mol\% $\left[\mathrm{Cu}(\mathrm{MeCN})_{4}\right] \mathrm{OTf}$ (assuming full conversion) was taken at the end of the electrolysis and directly transferred to the catalysis reaction mixture. This resulted in full conversion to benzaldehyde. To determine if $2.2 \mathrm{~F} \mathrm{~mol}^{-1}$ is necessary to achieve full conversion to benzaldehyde, the electrolysis was performed as above with aliquots taken at time intervals corresponding to a range of 1.0-2.3 $\mathrm{F} \mathrm{mol}^{-1}$ (Fig. 1). ${ }^{48}$ The catalytic step requires a basic reaction medium and any residual triflic acid from the electrolysis step may neutralise the $\mathrm{N}$-methylimidazole present in the catalytic step. The sensitivity of the catalytic reaction was probed by spiking the reaction mixture with triflic acid and the efficiency of the reaction was found to be highly susceptible to the presence of triflic acid (Table S1). As such, one equivalent of $N$-methylimidazole was used in this experiment.

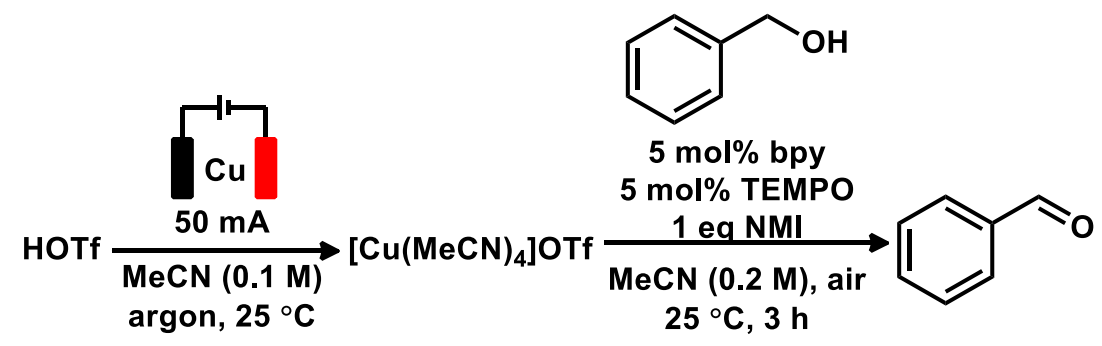




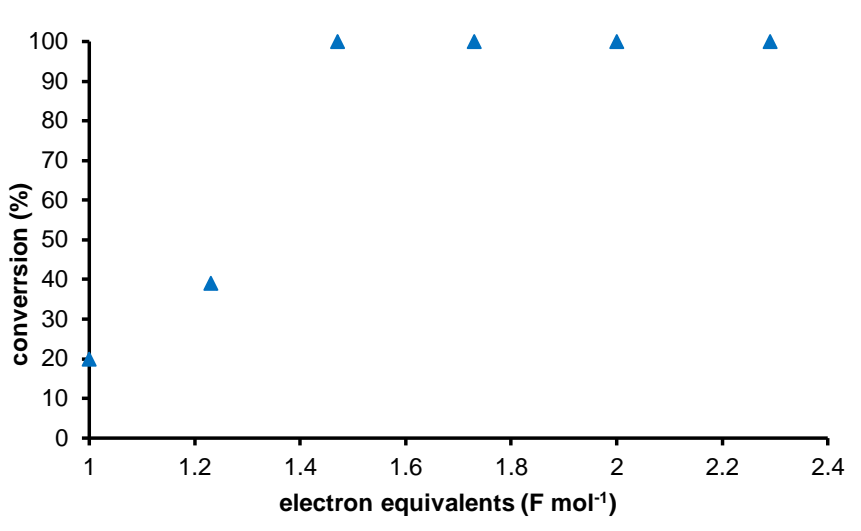

Figure 1: Conversion of benzyl alcohol to benzaldehyde with aliquots of the electrolysis taken at increasing electron equivalents.

When only 1.0 electron equivalent is used for the electrolysis step before an aliquot is transferred to the catalytic reaction, low conversion was observed (20\%). The conversion increases to $39 \%$ after $1.2 \mathrm{~F} \mathrm{~mol}^{-1}$ and reaches full conversion after $1.5 \mathrm{~F} \mathrm{~mol}^{-1}$. The increase in conversion for the catalytic step is potentially due to either the decreasing concentration of triflic acid or the increasing concentration of $\left[\mathrm{Cu}(\mathrm{MeCN})_{4}\right]$ OTf which effectively increases the catalyst loading. To confirm that only $1.5 \mathrm{~F} \mathrm{~mol}^{-1}$ are required, another electrolysis reaction was performed under identical conditions except with only $10 \% \mathrm{~N}$-methylimidazole and an aliquot was taken after $1.5 \mathrm{~F} \mathrm{~mol}^{-1}$ and transferred to the catalytic reaction resulting in full conversion to benzaldehyde.

Given the success of the on-demand synthesis and use of $\left[\mathrm{Cu}(\mathrm{MeCN})_{4}\right] \mathrm{OTf}$ under batch conditions, we began investigating its electrosynthesis under continuous flow conditions. The use of a continuous system provides numerous advantages including the ability to reduce the interelectrode gap, thus reducing resistance in solution and potentially increasing Faradaic efficiency. ${ }^{49}$ Furthermore, the ability to directly dispense the outflow of the reactor into the catalytic reaction mixture in an 'on tap' fashion provides process benefits as it is more straightforward than transferring aliquots via syringe and the use of a continuous flow system simplifies scale up. To this end, a continuous flow electrochemical reactor was used for the electrolysis step to produce $\left[\mathrm{Cu}(\mathrm{MeCN})_{4}\right]$ OTf and the outflow was dispensed directly into the catalytic aerobic oxidation of benzyl alcohol. We have previously reported the development of an electrochemical continuous flow reactor for the synthesis of $\mathrm{Cu}-\mathrm{N}$-heterocyclic carbene (NHC) complexes. ${ }^{47}$ In this instance we have used a scaled down version of the reactor which allows smaller volumes specifically for the production of catalytic species to be delivered into reactions..$^{50}$ Initially, reaction conditions similar to the batch electrolysis were employed involving $2.2 \mathrm{~F} \mathrm{~mol}^{-1}$ but with a lower current $(5 \mathrm{~mA})$ and lower concentration of triflic acid $(0.02 \mathrm{M})$. This was due to the decreased reaction volume achieved by the continuous system. 
The use of the continuous flow system allowed the production of $\left[\mathrm{Cu}(\mathrm{MeCN})_{4}\right]$ OTf to be produced faster than the optimised batch protocol with a $5 \mathrm{~mol} \%$ aliquot $(0.05 \mathrm{mmol})$ being produced in 36 minutes with a residence time of 14 minutes. This aliquot was dispensed directly into a batch catalysis reaction which resulted in full conversion after 3 hours (Scheme 3).

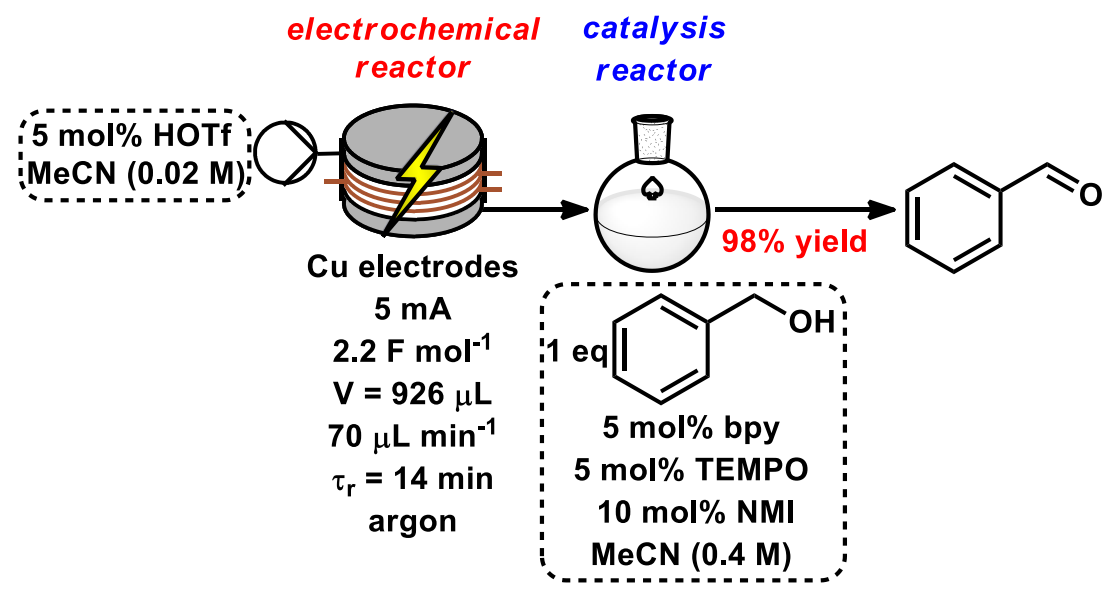

Scheme 3: Continuous flow synthesis of $\left[\mathrm{Cu}(\mathrm{MeCN})_{4}\right]$ OTf dispensed directly into the catalytic oxidation of benzyl alcohol.

To optimise the continuous flow synthesis of $\left[\mathrm{Cu}(\mathrm{MeCN})_{4}\right] \mathrm{OTf}$, we next investigated the Faradaic efficiency of the system. This was performed by increasing the flow rate of the electrolysis step and dispensing directly into a catalytic reaction. As the flow rate increased this shortened the time that the outflow of the electrochemical reactor had to be dispensed into the catalytic reaction to achieve a $5 \mathrm{~mol} \%$ aliquot and reduced the input of electron equivalents in the electrochemical step (Fig 2). Full conversion to benzaldehyde is observed with $1.6 \mathrm{~F} \mathrm{~mol}^{-1}$ (95\% at $\left.1.4 \mathrm{~F} \mathrm{~mol}^{-1}\right)$, which is similar to the batch protocol. Interestingly, as the amount of electron equivalents is reduced the conversion to benzaldehyde drops off much less rapidly compared to the batch protocol (Fig. 1). This is potentially derived from greater conversion of triflic acid to $\left[\mathrm{Cu}(\mathrm{MeCN})_{4}\right]$ OTf at lower electron equivalents as a result of better Faradaic efficiency. Under the optimised continuous flow conditions, a 5 mol\% aliquot of $\left[\mathrm{Cu}(\mathrm{MeCN})_{4}\right] \mathrm{OTf}$ could be delivered to the catalytic reaction in 25 minutes with a residence time of 9.5 minutes. 


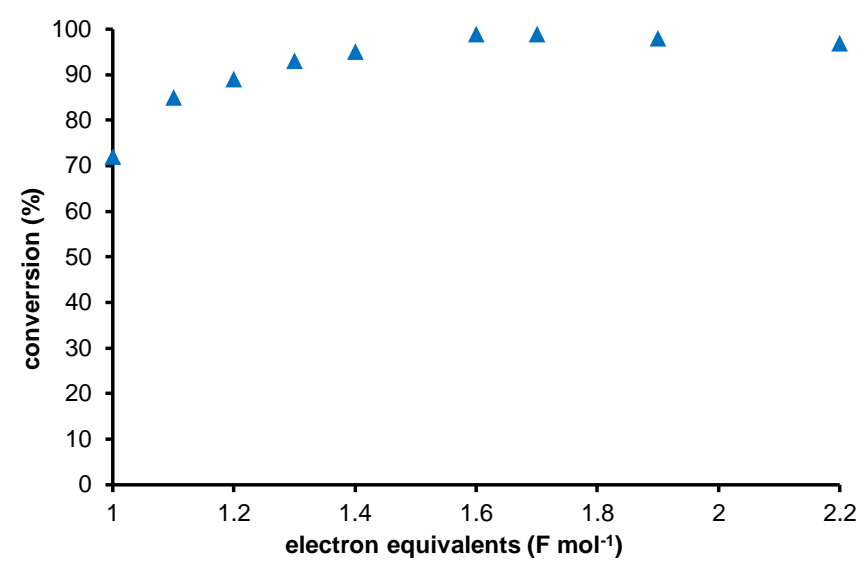

Figure 2: Conversion of benzyl alcohol to benzaldehyde using continuous flow reactor with increasing electron equivalents.

\section{Conclusions}

A high yielding electrochemical protocol for the synthesis of $\left[\mathrm{Cu}(\mathrm{MeCN})_{4}\right]$ OTf under both batch and continuous flow conditions was developed. Advantages of the electrochemical protocol over more traditional syntheses include high yield, very mild conditions, the use of bench stable and inexpensive starting materials, elimination of water being incorporated into the product and simple / no purification. The electrochemical protocol can be used for the ondemand synthesis of $\left[\mathrm{Cu}(\mathrm{MeCN})_{4}\right]$ OTf using both batch and continuous flow methodologies which presents a particular advantage for this sensitive $\mathrm{Cu}^{\prime}$ salt. The on-demand synthesis has been demonstrated by an aerobic oxidation of benzyl alcohol to benzaldehyde which requires $\mathrm{Cu}^{\prime}$ rather than $\mathrm{Cu}^{\prime \prime}$ to proceed efficiently. Extending this protocol to produce other metal triflates (e.g. $\mathrm{Pd}(\mathrm{OTf})_{2}$ ) would be desirable as this would negate several challenges associated with the common synthetic routes used today, in particular the incorporation of water which can cause problems in catalysis.

\section{Acknowledgements}

We acknowledge financial support from EPSRC (EP/R009406/1), and Dr Christiane Schotten for useful discussions.

\section{References}

1. T. Kishida, T. Yamauchi, Y. Kubota and Y. Sugi, Green Chem., 2004, 6, 57-62.

2. I. Bodachivskyi, U. Kuzhiumparambil and D. B. G. Williams, Fuel Process. Technol., 2019, 195, 106159.

3. M. Helou, O. Miserque, J.-M. Brusson, J.-F. Carpentier and S. M. Guillaume, ChemCatChem, 2010, 2, 306-313. 
4. L. Daniel, C. B. Rasrendra, A. Kloekhorst, A. A. Broekhuis, R. Manurung and H. J. Heeres, J. Am. Oil Chem. Soc., 2014, 91, 325-336.

5. L. Zhu, X. Sheng, Y. Li, D. Lu, R. Qiu and N. Kambe, Org. Lett., 2019, 21, 6785-6789.

6. J. Liang, J. Han, J. Wu, P. Wu, J. Hu, F. Hu and F. Wu, Org. Lett., 2019, 21, 6844-6849.

7. P.-A. Payard, Y.-T. Zheng, W.-J. Zhou, L. Khrouz, L. Bonneviot, R. Wischert, L. Grimaud and M. Pera-Titus, Eur. J. Org. Chem., 2020, 3552-3559.

8. R. Tang, Z. Shao, J. Wang, Z. Liu, Y.-M. Li and Y. Shen, J. Org. Chem., 2019, 84, 8177-8184.

9. J. Zhang, Y. Zhang, S. Geng, S. Chen, Z. Liu, X. Zeng, Y. He and Z. Feng, Org. Lett., 2020, 22, 2669-2674.

10. P. J. Figiel, A. Sibaouih, J. U. Ahmad, M. Nieger, M. T. Räisänen, M. Leskelä and T. Repo, Adv. Synth. Catal., 2009, 351, 2625-2632.

11. P. Gamez, I. W. C. E. Arends, R. A. Sheldon and J. Reedijk, Adv. Synth. Catal., 2004, 346, 805811.

12. D. GeißImeir, W. G. Jary and H. Falk, Monatsh. Chem., 2005, 136, 1591-1599.

13. T. Iwahama, Y. Yoshino, T. Keitoku, S. Sakaguchi and Y. Ishii, J. Org. Chem., 2000, 65, 65026507.

14. N. Jiang and A. J. Ragauskas, J. Org. Chem., 2006, 71, 7087-7090.

15. S. Mannam, S. K. Alamsetti and G. Sekar, Adv. Synth. Catal., 2007, 349, 2253-2258.

16. I. E. Markó, A. Gautier, R. Dumeunier, K. Doda, F. Philippart, S. M. Brown and C. J. Urch, Angew. Chem. Int. Ed., 2004, 43, 1588-1591.

17. G. Ragagnin, B. Betzemeier, S. Quici and P. Knochel, Tetrahedron, 2002, 58, 3985-3991.

18. M. F. Semmelhack, C. R. Schmid, D. A. Cortés and C. S. Chou, J. Am. Chem. Soc., 1984, 106, 3374-3376.

19. J. M. Hoover and S. S. Stahl, J. Am. Chem. Soc., 2011, 133, 16901-16910.

20. T. Lopez-Dellamary, J. A. Sampedro, G. Carlos, M. Fontes and T. Ogura, Transit. Met. Chem., 1978, 3, 342-344.

21. J. S. Ovens, P. R. Christensen and D. B. Leznoff, Chem. Eur. J., 2016, 22, 8234-8239.

22. J. K. Irangu and R. B. Jordan, Inorg. Chem., 2003, 42, 3934-3942.

23. J. Irangu, M. J. Ferguson and R. B. Jordan, Inorg. Chem., 2005, 44, 1619-1625.

24. R. G. Salomon and J. K. Kochi, J. Am. Chem. Soc., 1973, 95, 1889-1897.

25. R. Datta, M. Sumalatha and S. Ghosh, J. Chem. Sci., 2016, 128, 1019-1023.

26. D. Holt and M. J. Gaunt, Angew. Chem. Int. Ed., 2015, 54, 7857-7861.

27. D. C. Marelius, E. H. Darrow, C. E. Moore, J. A. Golen, A. L. Rheingold and D. B. Grotjahn, Chem. Eur. J., 2015, 21, 10988-10992. 
28. C. Schotten, T. P. Nicholls, R. A. Bourne, N. Kapur, B. N. Nguyen and C. E. Willans, Green Chem., 2020, 22, 3358-3375.

29. T. P. Nicholls, C. Schotten and C. E. Willans, Curr. Opinion Green Sus. Chem., 2020, 26.

30. T. H. Meyer, I. Choi, C. Tian and L. Ackermann, Chem., 2020, 6, 2484-2496.

31. S. B. Beil, D. Pollok and S. R. Waldvogel, Angew. Chem. Int. Ed. 2021, DOI: 10.1002/anie.202014544.

32. J. M. Hoover, J. E. Steves and S. S. Stahl, Nat. Protoc., 2012, 7, 1161-1166.

33. J. E. Steves and S. S. Stahl, J. Am. Chem. Soc., 2013, 135, 15742-15745.

34. B. L. Ryland and S. S. Stahl, Angew. Chem. Int. Ed., 2014, 53, 8824-8838.

35. J. E. Steves and S. S. Stahl, J. Org. Chem., 2015, 80, 11184-11188.

36. J. M. Hoover, B. L. Ryland and S. S. Stahl, J. Am. Chem. Soc., 2013, 135, 2357-2367.

37. J. M. Hoover, B. L. Ryland and S. S. Stahl, ACS Catal., 2013, 3, 2599-2605.

38. B. L. Ryland, S. D. McCann, T. C. Brunold and S. S. Stahl, J. Am. Chem. Soc., 2014, 136, 1216612173.

39. M. C. Ryan, L. D. Whitmire, S. D. McCann and S. S. Stahl, Inorg. Chem., 2019, 58, 10194-10200.

40. J. F. Greene, J. M. Hoover, D. S. Mannel, T. W. Root and S. S. Stahl, Org. Proc. Res. Dev., 2013, $17,1247-1251$.

41. J. F. Greene, Y. Preger, S. S. Stahl and T. W. Root, Org. Proc. Res. Dev., 2015, 19, 858-864.

42. J. E. Steves, Y. Preger, J. R. Martinelli, C. J. Welch, T. W. Root, J. M. Hawkins and S. S. Stahl, Org. Proc. Res. Dev., 2015, 19, 1548-1553.

43. B. R. M. Lake, E. K. Bullough, T. J. Williams, A. C. Whitwood, M. A. Little and C. E. Willans, Chem. Commun., 2012, 48, 4887-4889.

44. M. R. Chapman, S. E. Henkelis, N. Kapur, B. N. Nguyen and C. E. Willans, ChemistryOpen, 2016, 5, 351-356.

45. S. Fukuzumi, Y.-M. Lee and W. Nam, Chem. Eur. J., 2018, 24, 5016-5031.

46. U. Bertocci and D. D. Wagman, in Standard potentials in aqueous solution, eds. A. J. Bard, R. Parsons and J. Jordan, Marcel Dekker, Inc., New York, 1985, ch. 11I, pp. 46-51.

47. M. R. Chapman, Y. M. Shafi, N. Kapur, B. N. Nguyen and C. E. Willans, Chem. Commun., 2015, $51,1282-1284$.

48. H. R. Stephen, C. Schotten, T. P. Nicholls, M. Woodward, R. A. Bourne, N. Kapur and C. E. Willans, Org. Proc. Res. Dev., 2020, 24, 1084-1089.

49. S. M. H. Hashemi, P. Karnakov, P. Hadikhani, E. Chinello, S. Litvinov, C. Moser, P. Koumoutsakos and D. Psaltis, Energ. Environ. Sci., 2019, 12, 1592-1604. 
50.

C. Schotten, C. J. Taylor, R. A. Bourne, T. W. Chamberlain, B. N. Nguyen, N. Kapur and C. E. Willans, React. Chem. Eng., 2021, 6, 147-151. 